\title{
Enhancing on-line Blended Learning Systems using a new Human-Computer Interaction Educational Methodology
}

\author{
Ismael Pascual-Nieto, Diana Pérez-Marín, Mick O’Donnell \\ and Pilar Rodríguez \\ Universidad Autónoma de Madrid \\ Spain
}

\section{Introduction}

The Internet has given rise to one of the latest revolutions in Education. While in the past, students learned primarily passively, by attending lectures given by human teachers, today the student can become an active agent in the learning process through the use of web-based educational systems.

This revolution has also affected the assessment of courses (Peat \& Franklin, 2002). Traditionally, assessment focused on paper \& pencil written exams. Web-based educational systems on the other hand have favoured the introduction of different types of summative and formative assessment, in which formative assessment is used to teach and not only to score the student's work.

However, the use of web-based learning and assessment in isolation from traditional teaching has been shown to present problems, such as the loss of the student-teacher relationship (Chung \& O'Neill, 1997). Therefore, Blended Learning has appeared, proposing the combination of traditional teaching methods with the use of computers for education (Graham, 2006). Following this approach, the student-teacher relationship is not lost, but the roles change: the teacher becomes a guide who facilitates learning and the student is in charge of his/her own learning process.

The use of Blended Learning systems has not become as widespread as it could become. We believe that one reason for the slow uptake is that many Blended Learning systems are designed by Computer Science teachers for Computer Science students, and because the designer is aware that the intended users have reasonable technical skills, they do not put much attention into the user-friendliness of the system.

We believe that current systems could be much improved if they were designed according to Human-Computer Interaction (HCI) principles. Taking such an approach, Blended Learning systems would be more accessible for everyone, and not only for those with Computer Science training.

Here, in this chapter, we present one solution to this problem: a methodology for the management of human-computer interaction within Blended Learning systems. 
This chapter is structured as follows: firstly we survey the existing work in the relevant fields (Blended Learning, Computer Assisted Assessment, and Human-Computer Interaction). Then we describe our proposed HCI Educational Methodology, and provide two case studies to illustrate the methodology. Finally, we present our conclusions drawn from the results achieved in the case studies and some lines of future work.

\section{Related work}

Given the multidisciplinary nature of the work presented in this chapter, no single field can be highlighted as most relevant to our work. Therefore, in this section, an introduction to the fields of Blended Learning, Computer Assisted Assessment and Human-Computer Interaction is provided.

\subsection{Blended Learning}

Blended Learning systems combine traditional teaching methods with the application of the new Information and Communication Technologies (ICTs) for education (Graham, 2006). Combining these approaches, students continue to learn from lectures with their teachers, while, outside of class, they can gain additional training from on-line courses, running on any computer connected to the Internet.

In recent years, e-learning systems have been adopting the Blended Learning approach because Blended Learning systems have the advantages of e-learning (flexibility in time and location, adaption to particular user needs, etc.), without its disadvantages (teacher-student relationship broken, isolation feeling in front of the computer, etc.)

However, the use of Blended Learning systems has still not spread to all educational institutions, largely because of issues of its own (Garrison \& Kanuka, 2004). It is not just that teachers and students need to adapt to new computer technology. The introduction of Blended Learning systems into an educational institution requires the involvement at all levels, including administration and support services: the development of policies for the integration of computers as an educational resource; the provision of funding for the development and management of different Blended Learning programs for different areas of knowledge, and the systematic evaluation of the degree of user satisfaction of the Blended Learning program among students and teachers to test its success.

The use of Blended Learning program might be rejected simply because of technological challenges, if not all teachers and students can be assumed to have necessary technological skills to use the software (Kim, 2007). This could be why the uptake of Blended Learning systems has been strongest in Computer Science departments (Howard et al., 2006; Kim, 2007; Fong, 2008).

Our contribution to this field is to provide a methodology detailing how to design Blended Learning systems so that they are easy to use for people without any technical training, and thus to lessen the rejection of Blended Learning programs for this reason.

In particular, our focus is on formative assessment, as we believe that a Blended Learning program can operate effectively with the content of the course being delivered by teachers through lectures, while the online component is used by the student to review the content after class. 


\subsection{Computer Assisted Assessment}

The increasing use of computers for educational assessment had led to the creation of the field of Computer Assisted Assessment (CAA) (Mcgrath, 2003; Mitchell et al., 2003; Palmer \& Richardson, 2003). CAA can be defined as the field that studies how computers can effectively be used to assess students' learning progress. Originally, CAA was limited to just Multiple Choice Questions (MCQs) and fill-in-the-blank exercises, despite the general opinion in the field that these types of assessment are not enough by themselves to measure higher cognitive skills (Birenbaum et al., 1992; Sigel, 1999; Mitchell et al., 2003).

Therefore, new and more sophisticated types of assessment were created, such as simulation exercises or assessment of students' free-text answers or essays (Valenti et al., 2003). However, many argued that these types of assessment were too complex and sophisticated to be performed by computers (Hearst, 2000).

In particular, there have always been detractors dismissing the idea that a computer could grade human essays. There are still today researchers who do not consider that automatic grading is possible. These researchers claim that computers do not have common sense and thus are not able to understand the students' answers. However, the advances in other research fields such as Natural Language Processing (NLP) have provided the means of overcoming this limitation up to certain point (Valenti et al., 2003).

Currently, there are more than thirty different free-text CAA systems working in academic institutions and companies. They are based on the use of different NLP techniques such as Latent Semantic Analysis, Information Extraction, or statistical techniques (Deerwester et al., 1990; Mitchell et al., 2003; Mitkov, 2003).

It would be pleasing to have one standard metric to measure the goodness of the automatic evaluation of students' free-text answers, and to be able to highlight one of these free-text CAA systems as the best one. However, there is no consensus among free-text CAA researchers, and thus we can only say that if we choose as a possible metric the correlation between the automatic scores and the scores marked by a human to the same set of questions, the state-of-the-art results range from 0.3 up to 0.95 (Pérez-Marín, 2007).

Our past work in this area made two contributions. Firstly, as we believe that free-text CAA systems should keep a model of each student so that the system can adapt the assessment to the needs of the particular student, we proposed the use of free-text Adaptive Computer Assisted Assessment (ACAA) systems. Free-text ACAA systems can be defined as free-text CAA systems able to assess students' free-text answers to non-ambiguous open-ended questions in an automatic and adaptive way (Pérez-Marín et al., 2006a).

Furthermore, free-text ACAA systems can also keep track of the students' conceptual evolution to generate Open Learner Models, that is, models that can be shown both to teachers and students, with information about which concepts should be reviewed, and which concepts have already been assimilated by the students (Pérez-Marín et al., 2007a).

Our second contribution has been to provide the ability to combine free-text assessment with self-assessment (Pascual-Nieto et al., 2008). This combination is beneficial to the freetext CAA field as automatic assessment is still not perfect, and whenever the system makes a mistake, the self-assessment allows the students to correct it.

\subsection{Human-Computer Interaction}

There have been many definitions of Human-Computer Interaction (HCI). For instance, Tufte (1989) defines HCI as follows: "Human-Computer Interaction can be understood as two 
potent information processors (a human and a computer) trying to communicate with each other using a highly restricted interface". Also, Preece (1994) offers an alternative definition: "Human-Computer Interaction is the discipline of designing, evaluating and implementing interactive computer systems to be used by humans".

Nevertheless, the great majority of these definitions share the same key idea: computer applications should be designed using principles that adapt their interface to make it easier for humans to use them (Berge, 1999). It has been claimed that even if a computer system is perfect from a technical point of view, the system could be regarded as a failure if users do not understand how to interact with it. Furthermore, the relevance of HCI and of making usable computer applications can also be seen in the fact that at least $48 \%$ of the code of computer applications is devoted to the interface (Myers, 1998).

Shneiderman (2002) stated that, while in the past Computer Science was more oriented to what computers could do, now Computer Science should be more oriented to what users can do with computers. This means that researchers not only from Computer Science, but also from Psychology, Sociology and other areas of knowledge should devise a set of principles to help designers to make computer applications user-friendly. Some of these principles are gathered below (Dumas \& Redish, 1999; Holzinger, 2005; Thimbleby, 2007):

- A different interface should be provided for novice than for expert users.

- It is important to keep all interfaces of a program consistent in their terminology, format and procedures.

- Users should be assisted with dialogue boxes whenever the task to be accomplished is complex. Moreover, if the task is composed of several subtasks, a flow diagram should be shown to indicate all the subtasks, and which subtask is currently being done.

- The messages provided to the users should be meaningful.

- The application should have on-line help.

- Users should be provided the same information in different representation formats to improve the accessibility of the application (e.g. a written message could also be read aloud to help blind people).

- The answer time of the application should be reasonable. Where tasks take a long time, a progress bar should indicate the amount of work done, and the amount of work to be done. In all cases, the user should receive confirmation to his or her actions (e.g. with a written message and/or a sound).

- If the computer application has a complex navigation structure, a site map or some kind of structure should be shown to help the user orientate himself or herself through the application.

- Cognitive aspects should be taken into account, such as the importance of color (e.g. avoid using aggressive combinations such as yellow/black or red/black) and the limited short-term memory of users (e.g. messages of previous screens should be repeated if they are going to be needed in the future).

These principles should be applied in the design of any computer application. In particular, our interest in this work is the application of $\mathrm{HCI}$ principles for educational applications, in which the users are teachers and students who may not have any computer training.

Some researchers are already aware of the importance of correctly managing HCI in educational applications (Borsook \& Higginbotham-Wheat, 1991; Drave, 2000; Rovai \& Barnum, 2003; Chou, 2003; Anderson, 2004). Their research has provided some results: the recipes of Borsook \& Higginbotham-Wheat (1991), which aim to make web-based learning 
applications more interactive; the framework of Chou (2003), intended to simplify the design of interactive web-based learning applications; or the distance education interactivity theory of Anderson (2004).

However, to our knowledge, there have been no proposals of a formal methodology to aide designers of web-based learning applications, and in particular for Blended Learning applications and their particularities. Our contribution in this chapter tries to fill that gap, by proposing a Human-Computer Interaction Educational Methodology for on-line Blended Learning systems, as we will describe in the next section.

\section{Human-Computer Interaction Educational Methodology for on-line Blended Learning systems}

The proposed HCI Educational Methodology presented here will be called M-I2P5. This methodology defines a set of methods or strategies to manage the interaction in a Blended Learning system between the teachers, students and the content of the system.

The definition of M-I2P5 starts with the identification of the entities (i.e. agents of the methodology), the data model, the interactions and the computational processes (i.e. actions performed by a computational layer o middleware to achieve an interaction goal), which are the target of the methods or strategies that will serve to manage the interaction in on-line Blended Learning systems. Figure 1 shows an interaction scenario with these elements.

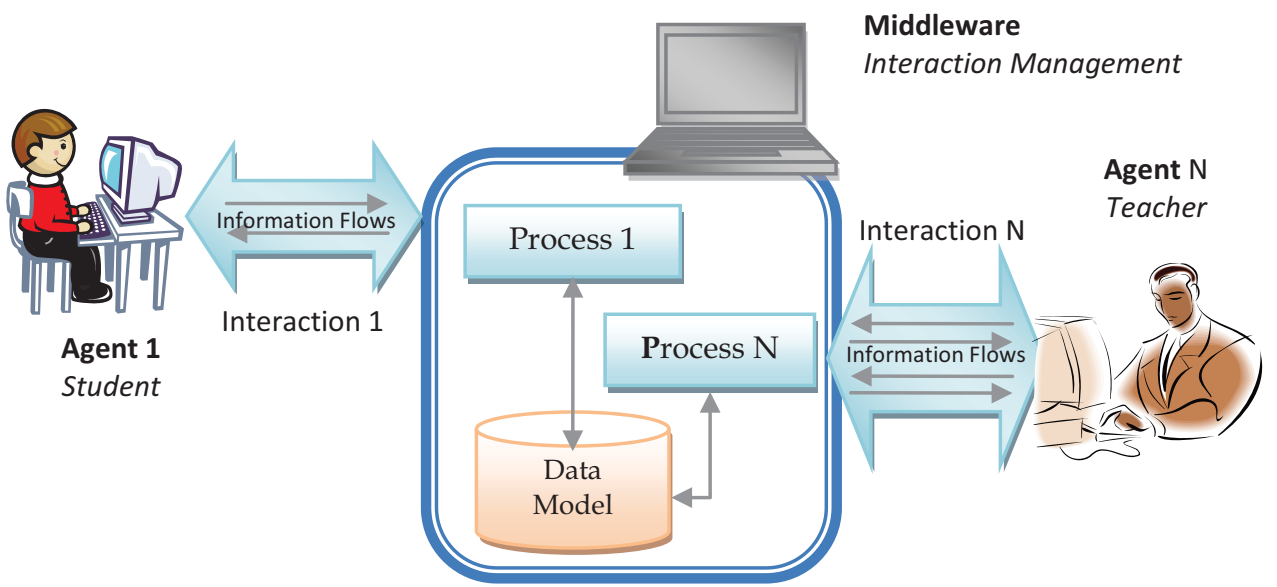

Fig. 1. Scenario with the proposed elements used to define the framework of M-I2P5

As can be seen in Figure 1, three different entities are distinguished: students, teachers and the computer application or middleware. The middleware is a key entity for the methodology as it is the entity in charge of implementing the methods to manage the interaction. In fact, two main types of interactions are considered:

- The student-middleware interaction: students log into the on-line Blended Learning system and interact with the computer (middleware). Similarly, the middleware has to provide a response to any action of the student in a way that s/he can understand, without having any kind of specific computer training. 
- The teacher-middleware interaction: teachers also need to interact with the middleware. Two subtypes of interactions can be distinguished here: firstly, the editing of the content of the Blended Learning course, and secondly, the monitoring of student learning progress (individuals or groups). It is important to remember here that while in an e-learning system the teacher totally disappears, in Blended Learning, the teacher changes his/her role from being the source of knowledge (in traditional teaching) to becoming a guide and facilitator of the learning.

Regarding the data model, note that while the kind of data that an on-line Blended Learning system needs to store can vary widely (questions, algorithms, numbers, texts, etc.), for most educational learning systems these data can all be expressed as a set of concepts and their relationships (Novak \& Gowin, 1984).

In this work we therefore propose to use a conceptual model as part of the data model. A conceptual model can be defined as a set of related concepts and their relationships. Each concept can be associated with text, figures, sounds, etc.

It is also important to bear in mind that besides the content of the course stored in the domain model, in order to make the on-line Blended Learning system adaptive to the student, a student model should also be kept (Brusilovsky \& Eklund, 1998). Moreover, the student model should be stored in a form that allows it to be shown to the students, allowing them to keep track of their progress (Dimitrova, 2001; Zapata-Rivera et al 2007). Therefore, we propose to use a conceptual model not only as part of the domain model, but also as part of the student model.

Finally, Figure 1 also shows the middleware as containing a set of computational processes, which can be defined as a series of actions which are carried out in order to correctly manage the interaction between pairs of the identified entities (students, teachers and the middleware itself). The description of these processes is presented in the following sections: the computational processes which manage the interaction between the student and the middleware are included in Section 3.1, and the computational processes which manage the interaction between the teacher and the middleware are included in Section 3.2.

\subsection{Processes for the management of the student-middleware interaction}

As can be seen in the scenario of Figure 2, three processes have been distinguished: the local assessment process, the global assessment reporting process and the learning process. All of them are described below. 


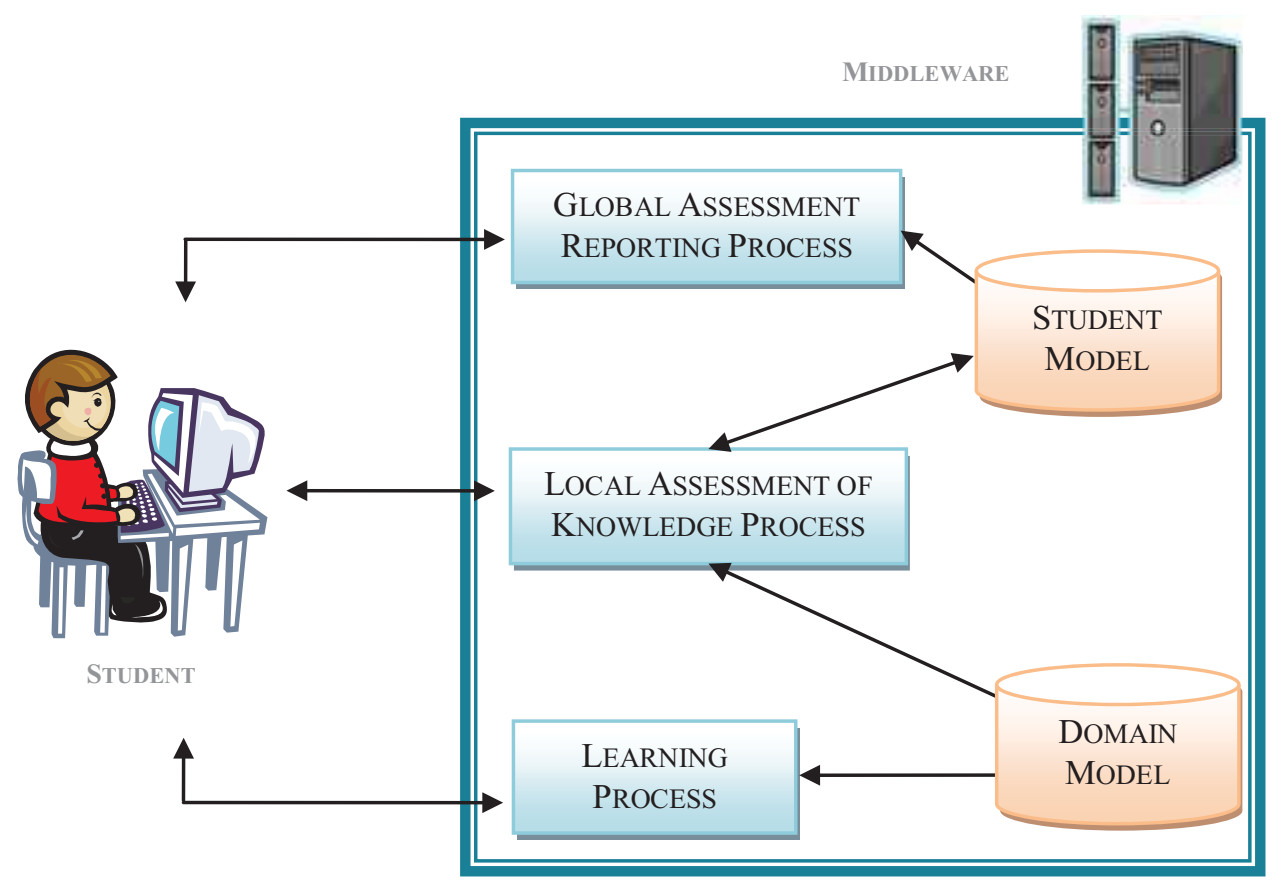

Fig. 2. Scenario showing computational processes for managing the student-middleware interaction in the methodology M-I2P5

\subsubsection{The local assessment process}

The goal of the local assessment process is to capture the student's knowledge for evaluating it. In order to achieve this goal, the procedure should be as follows:

1. The middleware asks the student a question.

2. The student answers the question, providing the middleware with indicators of how well s/he knows the answer.

3. The middleware evaluates the knowledge indicators and returns feedback to the student indicating the assessment.

Furthermore, from an interaction point of view, some HCI principles that should be taken into account in this procedure:

- To communicate following a dialogue metaphor: Human-Computer communication is facilitated when it is similar to Human-Human communication. Therefore, given that humans communicate with each other using dialogues, it is natural for us to communicate with computers using, if not dialogues (as they are still too complex to analyze from a Natural Language Processing point of view), at least dialogue metaphors.

- To adapt of the information presented to the student: each student, according to his or her learning style, can manage information in a different way. Thus, the information presented to them should be adapted to their abilities and preferences. 
- To limit the cognitive overload: human working memory is limited. Thus, the number of elements in the interface should also be limited and also important ideas that are needed from one screen to another should be repeated.

- To provide immediate feedback: for each exercise or question the student should be given textual or visual feedback. It is an HCI principle that each action of the user has to have a visible reaction. That is, for each question answered by the student (action), the system should provide the student with feedback (reaction).

- To provide the possibility of self-assessment: the student should not be regarded as a passive agent in the student-middleware interaction. Rather, the student should be able to intervene not only in their learning process, but also in their assessment process, as an active critique part. When the automatic assessment of the system is not perfect (e.g., as when free text answers are assessed), the student should have scope to modify the assessment, perhaps with later review by the teacher.

\subsubsection{The global assessment reporting process}

The goal of global assessment reporting process is to provide to the students global feedback information about their progress in the course. Hence, this process is different from the previous process in that it provides assessment for the whole course, rather than a single question. To achieve this goal, there are five important HCI principles that any on-line Blended Learning system designer should take into account:

- To provide multimodal information: all information, including the feedback, should be presented in several representation formats. That way, different aspects can be highlighted in each representation, and in the case that one student cannot understand one representation format, $\mathrm{s} /$ he would still be able to understand one of the others.

- To provide a summary of the information: as with the local assessment process, limited working human memory should be taken into account (indeed this factor is more important here due to the larger amount of information to present). Thus, summaries should be provided instead of providing all detailed information on one screen.

- To provide feedback: this feedback is not the same than the immediate feedback of the local assessment process, but feedback that should be available to the student anytime $\mathrm{s} /$ he wants it. This is particularly relevant to many Blended Learning systems in which the goal of the assessment is not summative (i.e. to score the students), but formative (i.e. to teach with feedback adapted to the mistakes found in the answers provided by the students).

- To show state indicators: students should also be aware of the subtasks needed to pass the course. Furthermore, the system should mark the level of progress made by each student in each subtask. Thus, the student can identify which subtasks need more work, and which have already been successfully completed, and his/her efforts can be oriented towards the pending subtasks.

- To allow students to review their previous work: even if a student has completed a subtask, s/he should be permitted to review the work done. For instance, a history of already passed exercises could be provided. In this history, both theoretical and practical content could be stored together to allow students to review the theory of the course with practical examples. 


\subsubsection{The learning process}

The goal of the learning process is to manage the interaction between the student and the middleware whenever the student is learning new content. The difference with the previous processes is that their focus was more on assessment (albeit formative assessment). Thus, in this process there is no capture of knowledge from the student, rather, it is the student who captures knowledge from the system.

Some HCI principles that designers should take into account when implementing this process are similar to the ones previously explained for assessment, but taking into account that here the focus is on teaching and not on evaluating:

- To promote the anchoring of new information with previous information: this HCI principle is based on the Meaningful Learning Theory (Ausubel, 1963), which claims that, in order to learn new concepts, students should understand previous concepts to which the new concepts are linked. In fact, according to Ausubel, this is the only way to learn something meaningfully. Thus, it is important that the organization of the structure of the course facilitates the anchoring of new information to previous one, and the existence of prerequisites.

- To generate local explanations for specific doubts: similarly to the local assessment process, and taking into account the limitation of the short term human memory, not only it is necessary to provide local feedback, but also to provide local explanations so that students can focus on those specific aspects of the course which could be more complex to understand.

- To remove irrelevant information: any irrelevant information might distract the attention of the student from the key content of the course. Thus, the interface should be designed to remove irrelevant elements and to help the student maintain their focus.

- To adapt the learning to each student: similarly to the assessment process, the learning should also be adapted to each student. Thus, not all students should be presented the same information, but according to each student profile, the information presented should be different.

- To provide multimodal information: as with the assessment process, students are not equally able to understand information presented in particular representation formats. That is, the adaptation of the content should also cover the representation format. For instance, according to each student learning style, some students may understand the content of the course shown in diagrams, while other students may understand it better presented as text. Moreover, even among students who prefer a certain learning style, not all of them may understand the concepts written in the same way. This could be solved by asking two or more teachers to collaborate when creating the Blended Learning course (considering also that usually one course is not imparted just by one teacher, but by several).

\subsection{Processes for the management of the teacher-middleware interaction}

As can be seen in Figure 3, two processes have been distinguished: the domain model creator process and the monitoring process. Both of these are described below. 


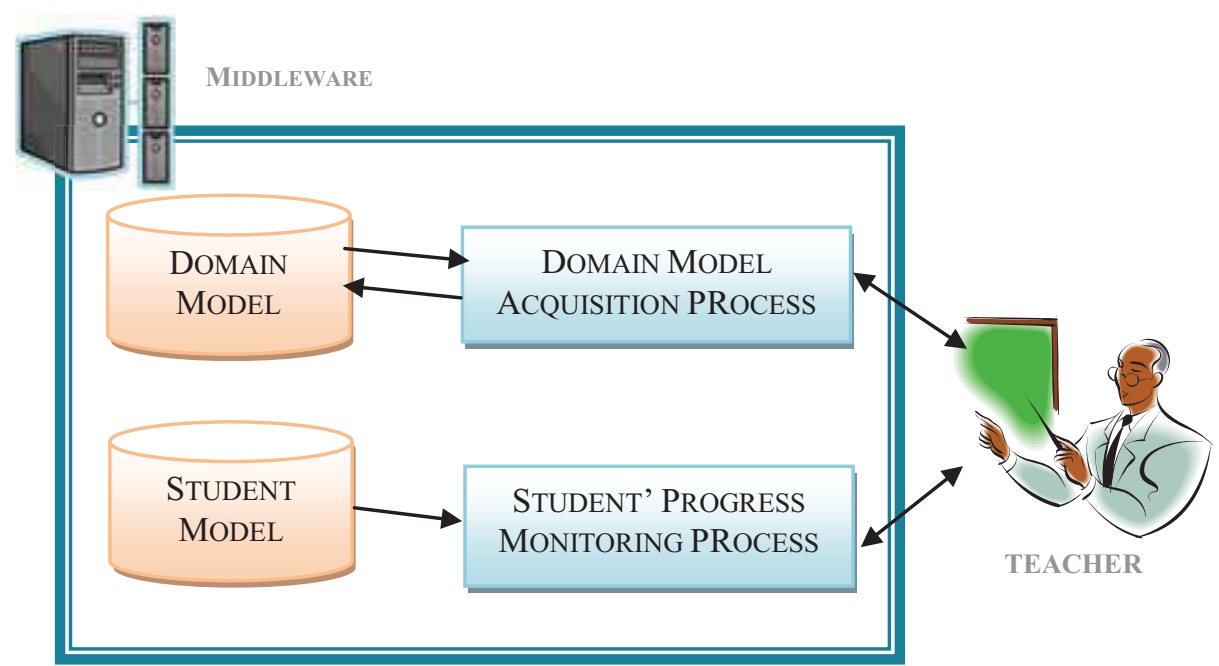

Fig. 3. Scenario showing the computational processes for managing the teacher-middleware interaction in the methodology M-I2P5

\subsubsection{The domain model acquisition process}

The goal of the domain model acquisition process is to manage the acquisition of the content of a Blended Learning course as provided by the teachers. However, the process of transferring that knowledge into the Blended Learning system is not easy. The goal of the domain model creator process is to facilitate the creation of the domain model of the course by making the authoring tool interface more targeted and easier to use.

Moreover, the process to manage the interaction between the teacher and the authoring tool is necessary because teachers tend to have more difficulties than students to learn to use online applications (Muir-Herzig, 2004). Therefore, the system should apply at least the following HCI principles:

- Allow teachers to use document editors: teachers should be permitted to complete the information for the domain model of the course by using text templates. Many educators know how to use document editors and they already have an electronic version of their course material. Therefore, by using a document editor to create the domain model, they would not have to learn a new computer application, and it would be easier for them to reuse previous material.

- Allow teachers to update the content of the course: teachers may need to modify information previously introduced in the course and they should have an easy way to do it with the authoring tool of the Blended Learning course, or just by uploading a new version of the text template. In any case, they should not be forced to find in which places they have to make the change, but the task should be facilitated by allowing them to introduce the modification and thus, automatically updating the rest of the course accordingly. 
- Allow teachers to use a natural hierarchy for the structure of the courses: usually teachers in their courses follow a hierarchical structure. Thus, they should be permitted to transfer this hierarchical structure to the electronic version of the course in case they want it.

- Limit the information presented in the screen: similarly to the processes for the student-middleware relationship, the interface to be used by the teachers should also be limited to the necessary information. This is because of the limited short term memory that humans have. Moreover, it is not advisable to make teachers scroll through the text as it deviates his or her attention from the main task of editing the course.

- Allow teachers to introduce multimedia content: on-line Blended Learning courses are not only composed of text. Therefore, the task of uploading videos, images, sounds, etc. should be easily found so that teachers feel encourage to use this feature.

\subsubsection{The student's progress monitoring process}

The goal of this process is to provide the teacher with the possibility of keeping track of the progress made by their students in an easy way. Many educational computer applications generate logs registering the actions performed by the students; however these logs are difficult to understand by non Computer Science experts (Mazza \& Dimitrova, 2005).

Therefore, a graphical interface should be presented to the teachers according to the following HCI principles:

- To organize the presentation of the information of the students' progress: teachers should be given the possibility of choosing by clicking on the name or photo of their students any group of students to which they want to see their progress. For teachers, it is intuitive to have a list of the class with the students' names (sometimes even with their photos). From this list, they can choose one student to get an individual report about him/her, or to choose a group of students, even the whole class to get a summary report from the individual reports of the students chosen.

- To provide complete and multimodal information: similarly to the assessment processes for the student, the feedback for the teacher should also be shown in several representation formats. That way, teachers can get a more complete view of the progress made by their students as each representation focuses on a different aspect.

- To guarantee that the information is updated: teachers would only consider updated information as the student reports may greatly change during the course. However, teachers are usually too busy to be able to update by hand the student reports. Therefore, an automatic mechanism should be activated that guarantees that the information is always updated, without loading the teacher with more work.

- To allow teachers to choose the level of detail of the students' progress reports: unlike students, teachers should have the possibility of looking the reports of any of their students up to the level of detailed the teachers required. Intuitive tools such as presenting an augmenting zoom to provide more details should be shown in the interface to make this task easier.

- To generate automatically reports out the tool: teachers may not have time to use the on-line Blended Learning tool on a weekly basis. However, this does not usually mean that they are not interested in looking at the reports. Therefore, teachers should be given, for instance, the possibility of automatically receiving the reports in their mail boxes. 


\section{Experiments and results}

In order to find out whether the use of the HCI Educational Methodology proposed for online Blended Learning systems allows these systems to be used without problems by students and teachers without any computer training, we implemented the processes of the previously described methodology in our own on-line Blended Learning tools, Atenea and COMOV, which did not implement M-I2P5, resulting in a system, now with M-I2P5 incorporated, called Will Tools (Pérez-Marín et al., 2006b; Pérez-Marín et al., 2007b).

The reason why the tools were not originally designed according to HCI principles lies in the fact that we are Computer Science teachers and our students are Computer Science students, who do not usually have any problem in using new software. However, our insight was that the systems could and should be easily adapted to use by students and teachers without computer training too.

The only requisite was to have a proper HCI Educational Methodology. Therefore, once we had devised the methodology, we implemented it in the Will Tools. Moreover, we tested the new tools with students and teachers from English Studies in our home university, who do not have any specific computer training.

The methodology has been evaluated using three metrics: usability tests, satisfaction questionnaires and personal interviews. Both objective and subjective aspects were addressed by the metrics.

Furthermore, the evaluation was done in two different case studies: the first focusing on the evaluation of the processes to manage the interaction between the student and the middleware (described in Section 4.1); and the second focusing on the evaluation of the processes to manage the interaction between the teacher and the middleware (described in Section 4.2).

\subsection{Case Study 1: evaluating the impact of the use of the proposed $\mathrm{HCl}$ Educational Methodology (M-I2P5) on the student-middleware relationship}

There are three main research questions to answer with the results of this case study:

- Do students with computer training notice the application of the principles of the proposed methodology M-I2P5 in Willow? This was tested by contrasting the level of satisfaction and frequency of use of Atenea+COMOV to the level of satisfaction and frequency of use of Willow. This question will be answered in Section 4.1.1.

- Do students without computer training use all Willow's features, and how does their behaviour when interacting with the system differ from the behaviour of the students with computer training? These two questions will be answered in Section 4.1.2.

The experiments performed were classified as indicated in Table 1.

\begin{tabular}{|c|c|c|}
\cline { 2 - 3 } \multicolumn{1}{c|}{} & $\begin{array}{c}\text { Profile without specific } \\
\text { computer training }\end{array}$ & $\begin{array}{c}\text { Profile with specific computer } \\
\text { training }\end{array}$ \\
\hline $\begin{array}{c}\text { System without M-I2P5 } \\
\text { (Atenea+COMOV) }\end{array}$ & --- & Computer Science Studies \\
\hline $\begin{array}{c}\text { System with M-I2P5 } \\
\text { (Willow, Willov, Willed) }\end{array}$ & English Studies & $\begin{array}{c}\text { Computer Science / } \\
\text { Telecomunications Studies }\end{array}$ \\
\hline
\end{tabular}

Table 1. Organization of the experiments 
The first experiment was performed during the 2006/2007 academic year. In this experiment, 24 (41\% of the class) Engineering students (with computer training) voluntarily used Atenea (see Figure 4) to review their Operating Systems course, from October to January.

The second experiment was performed during the 2007/2008 academic year. In this experiment, 22 (49\% of the class) English students (without computer training) voluntarily used Willow (see Figure 5) to review their Pragmatics course, from October to January.

The third and last experiment was also performed during the 2007/2008 academic year. In this experiment, 133 ( $77 \%$ of the class) Engineering students (with computer training) voluntarily used Willow to review their Operating Systems course, from May to June.

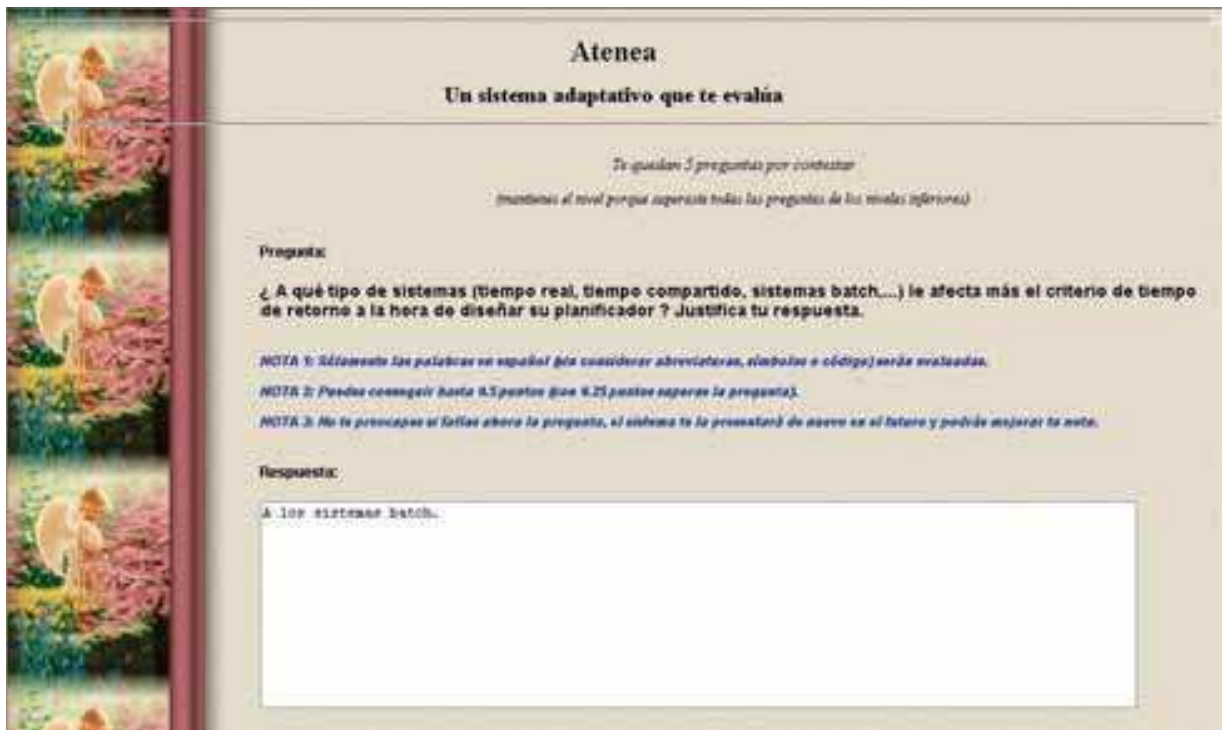

Fig. 4. Sample snapshot of Atenea (without M-I2P5) asking a question to the student

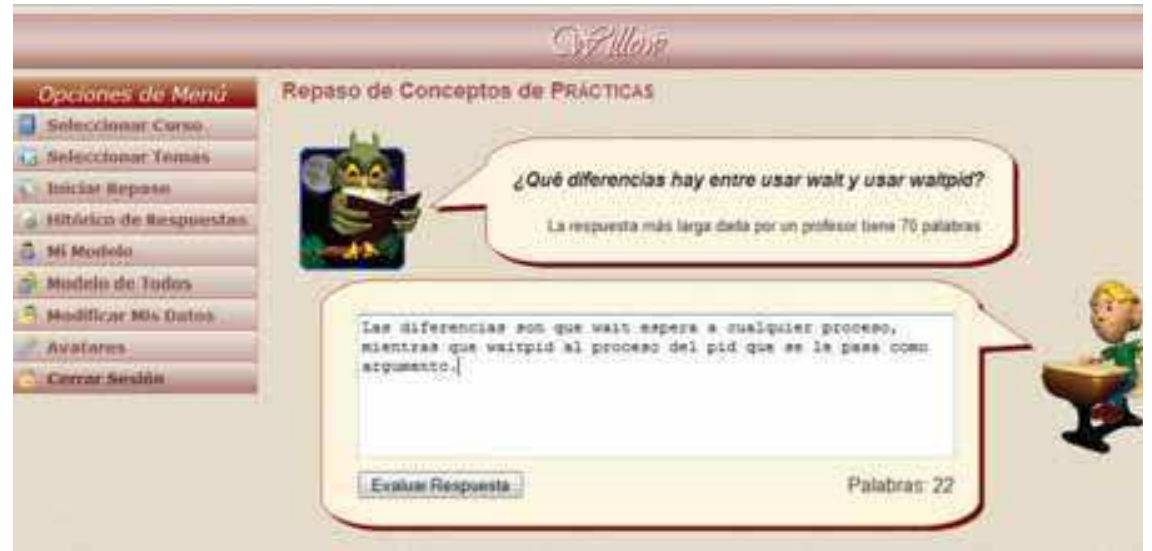

Fig. 5. Sample snapshot of Willow (with M-I2P5) asking a question to the student 


\subsubsection{Impact of the methodology for students with computer training}

In order to answer the question whether students with computer training would notice the application of M-I2P5 in Willow, the results achieved in the first experiment (using Atenea+COMOV without the methodology), and in the third experiment (using Willow with the methodology) were compared.

The students of both experiments were motivated in the same way: they were told that students with borderline fails would be passed if their scores in the system showed progress.

We also provided a 5-minute explanation of the goal of the systems and very little information about how to use it. We recommended the students to use the system on a weekly basis, rather than trying to review the whole course before the exam.

At the end of the course, we measured the frequency of use of the systems. Figure 6 shows a histogram with the frequency of use of Atenea by the 24 Engineer students of the first experiment. It can be seen how, in general, students did not follow our recommendation of using the system weekly. Rather, most of them used it only on the days just before the midterm exam in November and to the final exam in January. It is also important to highlight that the number of students using the system increased for the final exam. This could be considered as an indicator that the students found the system useful when reviewing for the mid-term exam. However, there are weeks in which no student logged into Atenea. Regarding the use of the monitoring tool COMOV, only 11 (46\%) students used the system during the semester.

Figure 7 shows a histogram with the frequency of use of Willow (with the methodology implemented) by the 133 Engineering students of the third experiment. It can be seen that the frequency of use is now higher (in fact, the scale of the diagram is not weeks but days). Moreover, it can be seen that they tended to use the system daily and not only the days before the exam, which was in June. From the logs of Willow, we observed that usually after answering a set of questions, students looked at their conceptual models or the conceptual models of the class with the information about their progress in the course.

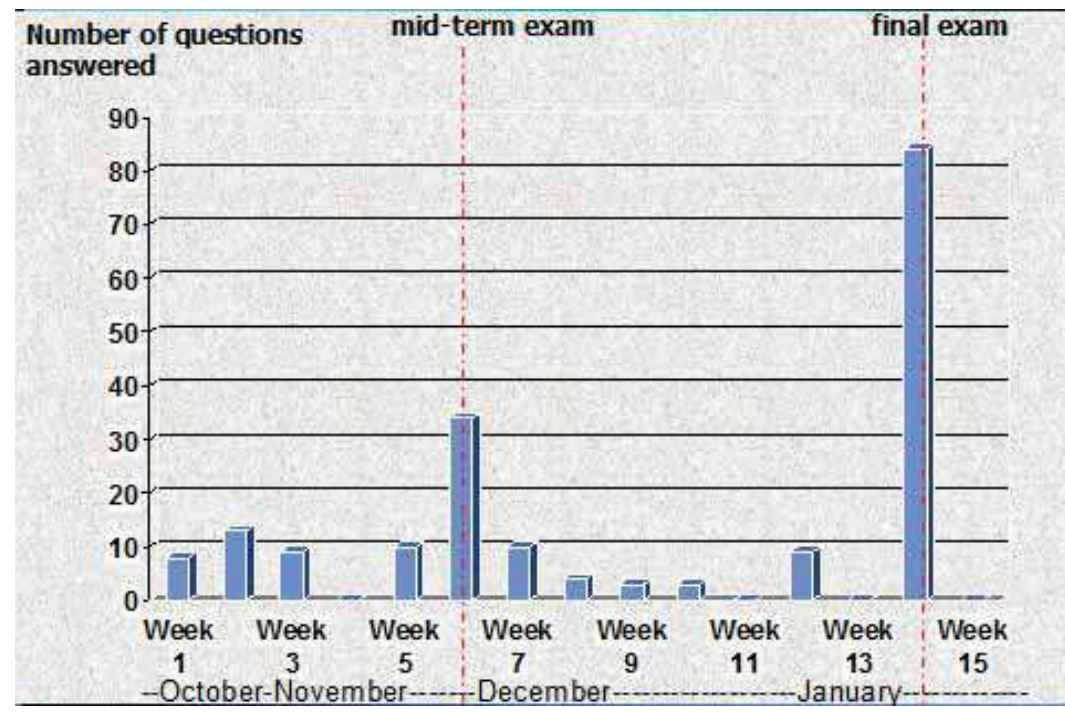

Fig. 6. Frequency of use of Atenea (in weeks) by students with computer training. 


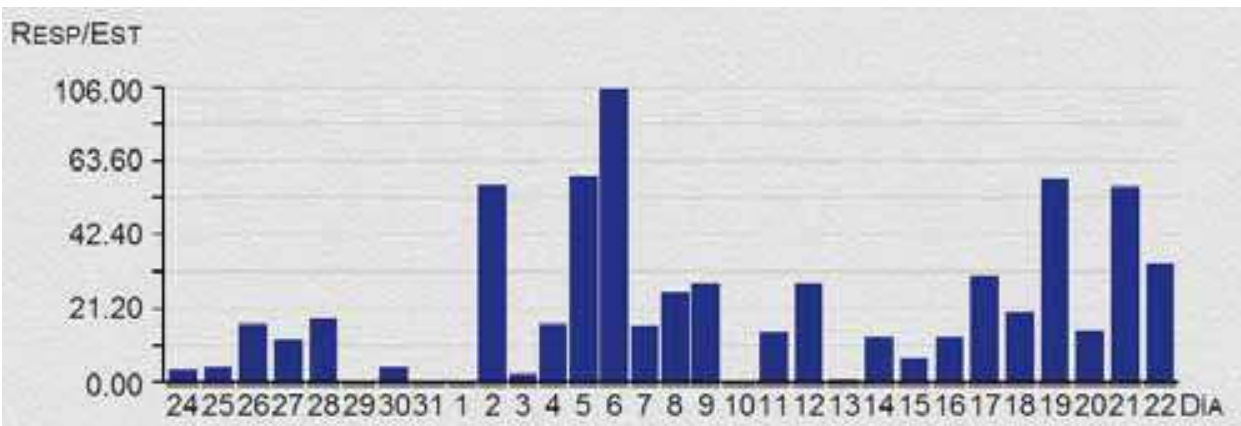

Fig. 7. Frequency of use of Willow (in days) by students with computer training

Regarding the level of satisfaction achieved by the students, they were asked to fill in a voluntary and anonymous satisfaction questionnaire. Given that filling in the questionnaire did not have any impact on the students' score, only $5(21 \%)$ of the students from the first experiment completed it. All these respondents considered Atenea useful and easy to use.

We also performed personal interviews of three randomly chosen students, each interview lasting for about 30 minutes and focusing on the student's opinion of the system, and how it could be improved. Firstly, all of them stated that they liked the system, and that it was useful to review concepts. Later, when we started asking about features of the system, the students declared that the problem they found was that the system was too strict, and sometimes it seemed unfriendly. Two of them declared that they felt they were being examined, and that they felt that they did not have freedom to interact with the system.

When the students were asked why only 11 students had used COMOV, they said that the COMOV system had not worked for them. COMOV had been developed using a particular browser, and, while the students had been told to use that browser, many of them did not, and thus $54 \%$ students could not get the system to work, and did not report the problem to us. $77 \%$ of the students in the third experiment filled in the satisfaction questionnaire because in the $2007 / 2008$ academic year, the questionnaire was given in hand to the students in class, and although it was also voluntary, teachers stressed its relevance. All of the students considered that Willow is easy to use and interesting. None of them said that Willow was unfriendly or too strict. On the contrary, most of the students stated that they liked reviewing the course with Willow because it is interactive and engaging. These students also used the global feedback features more, as they were integrated in Willow, and they did not have to use a different system such as COMOV.

\subsubsection{Comparison of the impact of the methodology between students with and without computer training}

In order to answer the questions whether students without computer training are able to use all Willow's features, and if their behaviour when interacting with the system is different from the behaviour of the students with computer training, the results of the second experiment (students without computer training using Willow), and of the third experiment (students with computer training using Willow) are compared.

Figure 8 shows the percentage of English Studies students who have used one or more of Willow's features without having any computer training, and just with a 5-minute 
explanation of Willow's goal and philosophy. We found that none of the students had any difficulty in using Willow. 95\% of the students chose different topics to review, $77 \%$ of the students changed his or her avatar in the system, $77 \%$ of the students visited the history of questions, $27 \%$ of the students changed his or her personal data, $68 \%$ of the students looked at the global feedback information; and, in fact $18 \%$ of the students tried to cheat.

All the students stated that Willow was friendly and useful, and they recommended it to any other student with or without computer training.
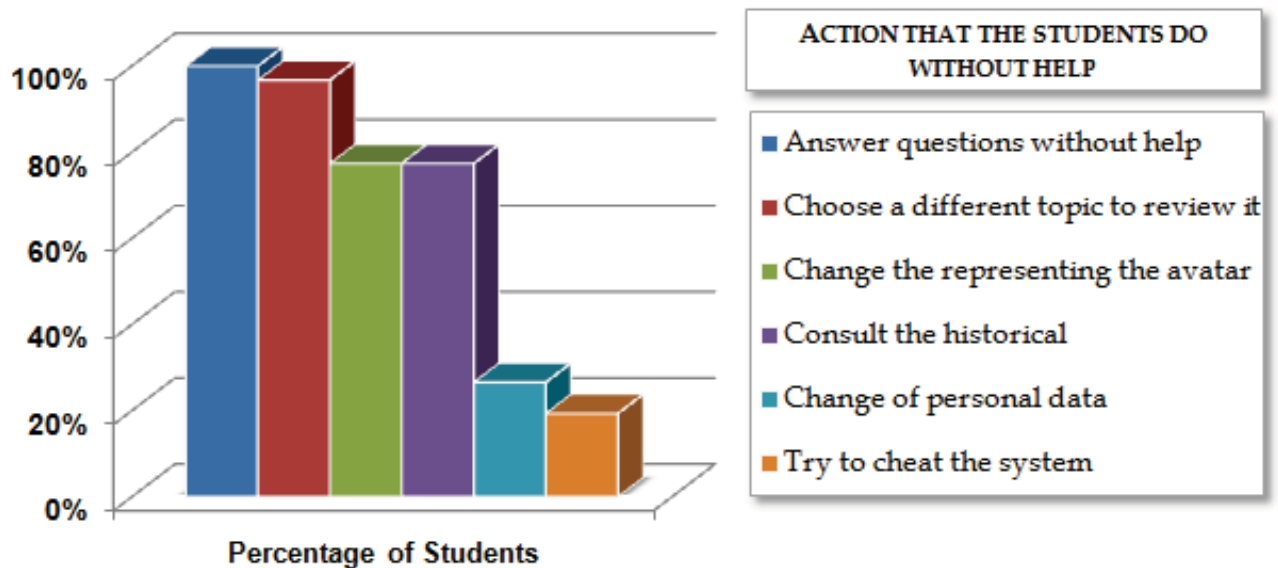

Fig. 8. Percentage of students of Pragmatics who used Willow's features with no help

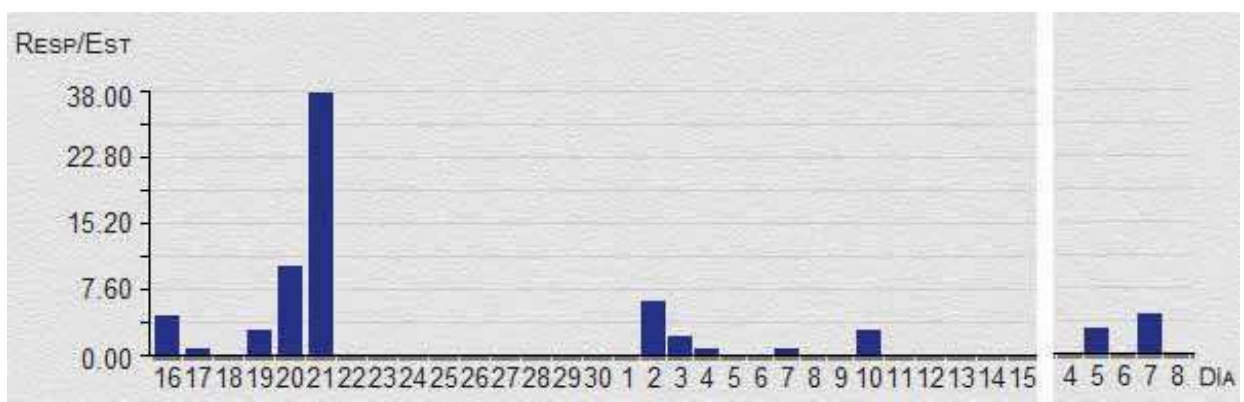

Fig. 9. Frequency of use of Willow (in days) by students without computer training

Figure 9 shows the frequency of use of Willow by the Pragmatics students. As can be seen, they logged into the system in different days, however the frequency of use of Willow is lower than in the case of students with computer training (see Figure 7)

Therefore, a first difference that can be highlighted between the interaction of students with and without computer training and Willow is that students without computer training tend to use it with a lower frequency.

Regarding the satisfaction achieved by the Pragmatics students, we also asked them to fill in an anonymous and voluntary satisfaction questionnaire. The results were very similar to the case of the first experiment, in which given that there was no impact in the final score of the 
subject and we were not their teachers, only 5 students completed the questionnaire. On the other hand, the results were different as all declared that Willow was easy to use, and interesting.

These satisfaction results are very similar to the ones reached by the students of the third experiment (students with computer training using Willow).

In general, the behaviour of students with and without computer training when interacting with Willow is similar. They find it useful and friendly and they are able to use all the features, without any restriction because of lack of computer knowledge. However, there are some differences such as the greater number of times that Pragmatics students used the selfassessment feature, and the longer answers they provided to the system.

\subsection{Case Study 2: evaluating the impact of the use of the proposed $\mathrm{HCl}$ Educational Methodology (M-I2P5) on the teacher-middleware relationship}

There are two main aspects to consider in this case study:

- The evaluation of the methods to acquire the domain model, which will be treated in Section 4.2.1.

- $\quad$ The evaluation of the methods to monitor student progress, which will be treated in Section 4.2.2

\subsubsection{Evaluation of the methods to acquire the domain model}

There are two main research questions regarding this evaluation: whether M-I2P5 increases the level of satisfaction of the teachers in creating and editing the content of the electronic courses, and how the use of the authoring tool differs depending on the computer training of the teachers.

The first experiment to answer those questions was performed in the 2006/2007 course. 6 teachers of the Computer Science department were asked to complete a usability test of the Atenea's question editor, and after that to fill in a satisfaction questionnaire (Alfonseca et al., 2005).

All of the teachers successfully completed the tasks of the usability test, and they considered that none of the tasks had been difficult. In fact, $67 \%$ of the teachers stated that the tool was quite easy to use. However, when we did a personal interview to the teachers, we observed that some of them would only consider the tool useful if it saves them time. For instance, they would like to have some feature in the tool which allows them to reuse electronic content of previous courses.

The second experiment was performed in the 2007/2008 academic course with 2 Pragmatics teachers without any computer training. They were also asked to complete the usability test with the Atenea's question editor. However, the teachers did not finish all the tasks, and they considered that it was difficult to find out where they should introduce the information and which steps they should follow to create the course. They also remarked on the inability to reuse previous electronic content.

Given that in the 2007/2008 academic course, we had already devised the methodology M-I2P5 and implemented it in Willed, we asked the Pragmatics teachers to repeat the usability test but this time with Willed. The result was that one of the teachers was able to finish all the tasks, and the other teacher that was more reluctant to the use of a new computer tool, was happy to find out that she could edit the content of the course with her 
document editor, and after that, she could upload the file to the system.

As there were only two teachers, we did not ask them to fill in a satisfaction questionnaire, but we did a personal interview to them. From these interviews, we concluded that Willed was considered easier to use, as it guides the user and they get graphical helps in each screen of the system.

The third experiment was performed in the 2007/2008 academic course with 2 Computer Science teachers using Willed. These teachers had also participated in the first experiment with Atenea's question editor, and they could compare the differences between the Atenea's questions editor (without M-I2P5) and Willed (with M-I2P5). Again, they could finish the tasks of the usability test without problems. In fact, this time, it took them less time to finish the test (it could also be because they had already used an authoring tool before). However, the most relevant difference became evident from the personal interviews, as now both teachers stated that they considered Willed more useful because it was easy to reuse content from previous courses.

\subsubsection{Evaluation of the methods to monitor student progress}

There are three main research questions regarding this evaluation: whether M-I2P5 increases the level of satisfaction of the teachers using the monitoring tool, and how the use of the monitoring tool Willov is different depending on the computer training of the teachers.

The first experiment to answer those questions was performed in the course 2006/2007. 6 teachers of the Computer Science department were asked to use COMOV (the monitoring tool without M-I2P5 implemented), and after that, to fill in a satisfaction questionnaire. The teachers rated the usability of the interface with a 3.8 value in a scale 0 -low usability to 5high usability. When the teachers were asked the reason for this mediocre value, they answered that despite liking the idea of the system, the interface was difficult to understand, and it was too static. Moreover, they thought that COMOV lacked important features such as providing frequency or performance graphs.

In the second experiment, we asked the 2 teachers of Pragmatics to use COMOV, and to give us their opinion. Again, the teachers did not understand some information presented by the system, and they stated that they would like to have graphs with information such as how long their students have reviewed each day. Furthermore, the Pragmatics teachers told us that they felt overloaded with too many computer tools, and that they did not have time to learn how to use all of them.

Therefore, when we showed them Willov, the monitoring tool of the Will Tools with M-I2P5 implemented, they highlighted the ability to send automatically generated reports to their email, and the automatic generation of interactive graphs with information about the work done by their students in Willow.

The third experiment was also in the 2007/2008 academic course, but this time with 2 Computer Science teachers. In particular, two of the six teachers who participated in the 2006/2007 academic course experiment, but this time instead of using COMOV (without M-I2P5), they were asked to use Willed (with M-I2P5 implemented).

Both teachers declared that the interface had been greatly improved and was more usable than COMOV's interface. They also highlighted the new features of choosing the students, topics, report generation and interactive monitoring graphs without needing to look at textual logs, or having to do the graph by hand. 
Regarding the question of the differences between the use of the monitoring tool Willov depending on the computer training of the teachers, in this case, they were greater than in the case of the authoring tool Willed.

Teachers with computer training indicated their preference of using Willov interactively online. In fact, the feature that they considered as the best one was the ability to choose any group of students just by clicking on their names, and get updated information about the group.

While teachers without computer training indicated that they felt overloaded with too many computer applications. In fact, the feature that they considered as the best one is the ability to automatically receive student reports in email.

\section{Conclusions and Future Work}

Human-Computer Interaction (HCI) has become a very important research field (Dix et al., 2003), with many international and national conferences devoted to its study (e.g. CHI, Persuasive, LOCA, ICEIS, WIAMIS, etc.). HCI principles should be taken into account when designing any computer system, including educational computer systems, in order to maximize their easiness of use, and to increase the level of satisfaction of users who interact with the systems.

However, to our knowledge, no formal methodology exists to gather how HCI principles can be used for educational applications. In particular, a HCI methodology for Blended Learning applications, in which the idea is to combine face-to-face instruction with computer activities during the class, or to review after class, and more types of studentmiddleware-teacher interactions have to be taken into account.

In this paper, we have proposed such a methodology, which has been called M-I2P5, and it has been implemented in a set of Blended Learning tools called Will Tools, which have been used since October 2006 by 6 teachers and 157 students with computer training, and by 2 teachers and 22 students without computer training.

Students with computer training were asked to interact with a version of the student system without the methodology implemented (called Atenea), and a version of the student system with the methodology implemented (called Willow). In both cases, students stated that the systems were useful to review concepts. However, in the case of Atenea, when we did a personal interview with some of them, they considered it was unfriendly and too strict. On the other hand, similar interviews for the users of Willow showed that they had not only used the system to review the course, but also enjoyed using the system.

Moreover, while the frequency of use of Atenea was weekly, and in some weeks no student logged into the system, the frequency of use of Willow was daily. In the case of the students without computer training, the frequency of use of Willow was also higher although not so constant.

None of the students without computer training found any problem using Willow, and even $18 \%$ of them tried to cheat the system. In fact, the use of Willow by students with and without computer training mainly differ in the attitude towards the system. While students with computer training regard it as an enjoyable way to review after class, students without computer training regard it as a self-assessment tool to complement the work done in class.

Teachers with computer training were asked to interact with a version of the authoring tool without the methodology M-I2P5 implemented (called Atenea's question editor), and also 
with a version of the authoring tool with M-I2P5 implemented (called Willed). In both cases, teachers were able to complete all the tasks of a usability test. However, the task took less time when using Willed than when using the Atenea's question editor. Moreover, when we interviewed the teachers, we found that they would not consider the system useful unless it allowed them to reuse previous content of other courses. This feature is included in Willed with M-I2P5, but it was not in the Atenea's question editor.

Moreover, neither of the teachers without computer training finished the usability test of the Atenea's question editor, while one of them finished the usability test of Willed. The other teacher preferred just to use her document editor and after that, uploaded the document in Willed.

Teachers with computer training also had the possibility of interacting with a version of the monitoring tool without having M-I2P5 implemented (called COMOV), and a version of the monitoring tool having M-I2P5 implemented (called Willov). In this case, the teachers declared a greater difference between COMOV and Willov.

Teachers without computer training did not use COMOV at all, and although teachers with computer training used it, they rated the interface as mediocre. On the other hand, they thought that Willov was highly useful to get information from any group of students they choose, and follow always updated performance and frequency graphs.

The main difference here between teachers with and without computer training was that while teachers with computer training were happy using Willov, teachers without computer training felt overloaded with too many computer applications. Hence they considered the possibility of receiving automatically generated student reports in their mail boxes as the most interesting. That way, they could have the monitoring information without having to use a new computer application. Nevertheless, the teachers without computer training also noticed that Willov seemed easier to use and was friendlier than COMOV.

Therefore, it can be concluded that using M-I2P5 has increased the level of satisfaction of both teachers and students with and without computer training. Even, in some cases, the use of M-I2P5 meant that teachers or students who were more reluctant to the use of Blended Learning tools, even thinking that the time and effort devoted to it was worthless, changed their mind and started using them noticing not only that the interface was easier to use, but also new interesting functions such as receiving information by mail.

Our main lines of future work in relation to M-I2P5 are:

- To improve M-I2P5 so that it includes other types of interaction such as studentstudent or teacher-teacher relationships. This could be interesting, for instance, to manage collaborative work between students, or between teachers.

- To evaluate the relative importance of each method in M-I2P5 through a comparative study on the impact of the implementation of each particular method identified by M-I2P5 in a system.

- $\quad$ To include in M-I2P5 accessibility methods as one of the main goals to manage the interaction of disabilities in Blended Learning tools.

- To study the management of interaction achieved when M-I2P5 is applied to other working systems, different from Atenea or COMOV, used for Blended Learning.

- To consider the use of a pedagogical model and its relationship with the methods of M-I2P5. 
The main lines of future work in relation to the Blended Learning tools are:

- To allow the students new ways of interaction where the conceptual model can be visualized as they are doing exercises.

- To explore the possibility of extending the dialogue metaphor by using a pedagogic conversational agent that engages students in guided conversations.

- To incorporate automatic Information Extraction techniques in the authoring tool, so that in the case of courses without previous content, teachers are shown a repository of possible reliable sources from the Internet such as University web pages, encyclopaedias, etc.

- To increase the flexibility of generating student reports in the monitoring tool. For instance, teachers can be given the ability to limit the information contained in the report.

Finally, we would also like to encourage other designers of Blended Learning tools to apply the proposed methodology M-I2P5 to their educational systems, and to report whether they get similar benefits to those we experienced when using the Will Tools with the methodology implemented.

\section{Acknowledgment}

This work has been sponsored by Spanish Ministry of Science and Technology, project TIN2007-64718.

\section{References}

Alfonseca, E. ; Carro, R. ; Freire, M. ; Ortigosa, A.; Pérez, D. \& Rodríguez, P. (2005). Authoring of Adaptive Computer Assisted Assessment of Free-text Answers. Educational Technology and Society (ETS), Special Issue on Authoring of Adaptive Hypermedia, Vol. 8, No. 3, 53-65.

Anderson, T. (2004), Theory and Practice of Online Learning, chapter Toward a theory of online learning, Athabasca University, 33-60.

Ausubel, D. (1963). The Psychology of Meaningful Verbal Learning, New York: Grune and Stratton.

Berge, Z. (1999). Interaction in post-secondary web-based learning. Educational Technology 41,1, 5-11.

Birenbaum, M.; Tatsuoka, K. \& Gutvirtz, Y. (1992). Effects of response format on diagnostic assessment of scholastic achievement. Applied psychological measurement, Vol. 16, No. 4, 353-363.

Borsook T.K. \& Higginbotham-Wheat N. (1991). Interactivity: what is it and what can it do for computer-based instruction? Educational Technology, Vol. 31, No. 5, 11-17.

Brusilovsky, P. \& Eklund, J. (1998). A Study of User Model Based Link Annotation in Educational Hypermedia. Journal of Universal Computer Science, Vol. 4, No. 4, 429-448.

Chou, C. (2003). Interactivity and interactive functions in web-based learning systems: a technical framework for designers, British Journal of Educational Technology, Vol. 34, No. 3, 265-279. 
Chung, G. \& O'Neill, H. (1997). Methodological approaches to online scoring of essays. Technical report 461, UCLA, National Center for Research on Evaluation, Student Standards, and Testing.

Deerwester, S.; Dumais, S.; Furnas, G.; Landauer, T. \& Harshman, R. (1990). Indexing by Latent Semantic Analysis. Journal of the American Society for Information Science, Vol. 41, No. 6, 391-407.

Dieng, R. (2000). Knowledge management and the Internet. IEEE Intelligent Systems and Their Applications, Vol. 15, No. 3, 14-17.

Dimitrova, V. (2001). Interactive open learner modelling. PhD thesis, University of Leeds, UK.

Dix, A.J., Finlay,J., Abowd, G. \& Beale, R. (2003). Human-Computer Interaction, 3nd edition, Prentice Hall, Englewood Cliffs, NJ, USA.

Drave W A. (2000). Teaching online LERN Books, River Falls, Wisconsin.

Dumas, J. S. \& Redish J. C. (1999). A practical guide to Usability Testing revised edition. Pearson Education Limited, 55-62

Fong, J. (2008). Web-Based Logging of Classroom Teaching Activities for Blended Learning. Advances in Web Based Learning, Springer Berlin / Heidelberg, 597-605.

Garrison, D.R. \& Kanuka, H. (2004). Blended learning: Uncovering its transformative potential in higher education, The Internet and Higher Education, Vol. 7, No. 2, Elsevier, 95-105.

Graham, C. (2006). The Handbook of Blended Learning: Global Perspectives, Local Designs, Pfeiffer, chapter Blended Learning Systems.

Holzinger, A. (2005). Usability engineering methods for software developers, Communications of ACM, Vol. 48, No. 1, 71-74.

Howard, L.; Remenyi, Z. \& Pap, G. (2006). Adaptive blended learning environments, Proceedings of the International Conference on Engineering Education, pp. 23-28.

M. Hearst. (2000). The debate on automated essay grading. IEEE Intelligent Systems, 5 (15), 22-37, 2000.

Kim, W. (2007). Towards a Definition and Methodology for Blended Learning, J. Fong and F. Lee Wang, in 'Blended Learning', Prentice Hall, Pearson Education, 1-8.

Mazza, R. \& Dimitrova, V. (2005). Generation of Graphical Representations of Student Tracking Data in Course Management Systems, Proceedings of the ninth International Conference on Information Visualisation, pp. 253-258.

Mcgrath, P. (2003). Assessing Students: Computer Simulation vs MCQs, Proceedings of the 7th Computer Assisted Assessment Conference, pp. 243-246.

Mitchell, T.; Aldridge, N.; Williamson, W. \& Broomhead, P. (2003). Computer Based Testing of Medial Knowledge, Proceedings of the 7th Computer Assisted Assessment Conference, pp. 249-267.

Mitkov, R. (2003). The Oxford Handbook of Computational Linguistics, Oxford University Press.

Muir-Herzig, R.G. (2004). Technology and its impact in the classroom. Computers and Education, Vol. 42, 111-131

Myers, B.A. (1998). A Brief History of Human Computer Interaction Technology. ACM interactions. Vol. 5, No. 2, 44-54

Novak, J. \& Gowin, D. (1984). Learning How to Learn, Cambridge University Press, Cambridge, U.K. 
Palmer, K. \& Richardson, P. (2003). On-line assessment and free-response input - a pedagogic and technical model for squaring the circle, Proceedings of the 7th Computer Assisted Assessment Conference, pp. 289-300.

Pascual-Nieto, I.; Perez-Marin, D.; O'Donnell, M. \& Rodriguez, P. (2008). Enhancing a freetext Adaptive Computer Assisted Assessment system with self-assessment features, Proceedings of the Eigth IEEE International Conference on Advanced Learning Technologies, pp. 252-256.

Peat, M. \& Franklin, S. (2002). Supporting student learning: the use of computer-based formative assessment modules. British Journal of Educational Technology, Vol. 33, No. 5, 515-523.

Perez-Marin, D. (2007). Adaptive Computer Assisted Assessment of free-text students' answers: an approach to automatically generate students' conceptual models, $\mathrm{PhD}$ thesis, Escuela Politecnica Superior, Universidad Autonoma de Madrid.

Pérez-Marín, D.; Alfonseca, E. \& Rodríguez, P. (2006a). On the dynamic adaptation of Computer Assisted Assessment of free-text answers, Proceedings of the Adaptive Hypermedia Conference, Lecture Notes in Computer Science, Vol. 4018, SpringerVerlag, 374-377.

Pérez-Marín, D.; Alfonseca, E.; Freire, M.; Rodríguez, P.; Guirao, J. \& Moreno-Sandoval, A. (2006b). Automatic Generation of Students' Conceptual Models underpinned by Free-Text Adaptive Computer Assisted Assessment, Proceedings of the IEEE International Conference on Advanced Learning Techniques (ICALT), 280-284.

Pérez-Marin, D.; Pascual-Nieto, I.; Alfonseca, E. \& Rodríguez, P. (2007a). Automatically Generated Inspectable Learning Models for Students, Proceedings of the international conference Artificial Intelligence in Education (AIED), 632-634.

Pérez-Marín, D. ; Pascual-Nieto, I. ; Alfonseca, E. ; Anguiano, E. \& Rodríguez, P. (2007b). A study on the impact of the use of an automatic and adaptive free-text assessment system during a university course, Blended Learning, Pearson, Prentice Hall, 186-195

Preece, J. (1994). Human-Computer Interaction. Pearson Education Limited: Essex, England.

Rovai, A. \& Barnum, K. (2003). Course Effectiveness: An Analysis of Student Interactions and Perceptions of Learning. Journal of Distance Education, Vol. 18, No. 1, 57-73.

Shneiderman, B. (2002). Leonardo's laptop, MIT Press Cambridge, Mass., U.S.A.

Sigel, I., ed. (1999). Development of mental representations: Theories and Applications, Lawrence Erlbaum Associates, New Jersey, U.S.A.

Thimbleby, H. (2007). Press on: principles of interaction programming, The MIT Press.

Tufte E.R., (1989). Visual Design of the User Interface. IBM Corporation, Armonk, N.Y., 1989

Valenti, S.; Neri, F. \& Cucchiarelli, A. (2003). An Overview of Current Research on Automated Essay Grading, Journal of Information Technology Education, 2, 319-330.

Zapata-Rivera, D.; Hansen, E.; Shute, V.; Underwood, J. \& Bauer, M. (2007). Evidence-based Approach to Interacting with Open Student Models, International Journal of Artificial Intelligence in Education, Vol. 17, No. 3, 273-303. 


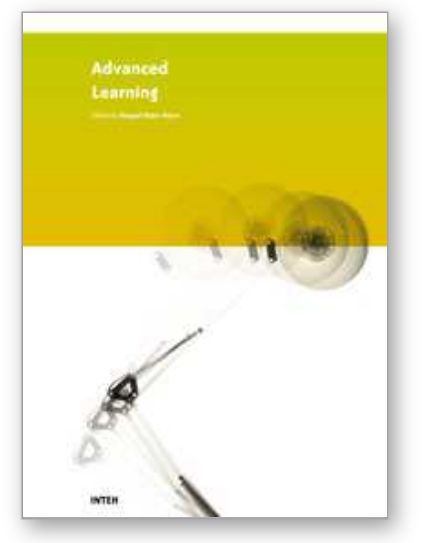

\author{
Advanced Learning \\ Edited by Raquel Hijn-Neira
}

ISBN 978-953-307-010-0

Hard cover, 444 pages

Publisher InTech

Published online 01, October, 2009

Published in print edition October, 2009

The education industry has obviously been influenced by the Internet revolution. Teaching and learning methods have changed significantly since the coming of the Web and it is very likely they will keep evolving many years to come thanks to it. A good example of this changing reality is the spectacular development of eLearning. In a more particular way, the Web 2.0 has offered to the teaching industry a set of tools and practices that are modifying the learning systems and knowledge transmission methods. Teachers and students can use these tools in a variety of ways aimed to the general purpose of promoting collaborative work. The editor would like to thank the authors, who have committed so much effort to the publication of this work. She is sure that this volume will certainly be of great help for students, teachers and researchers. This was, at least, the main aim of the authors.

\title{
How to reference
}

In order to correctly reference this scholarly work, feel free to copy and paste the following:

Ismael Pascual-Nieto, Diana Perez-Marin, Mick O'Donnell and Pilar Rodriguez (2009). Enhancing On-line Blended Learning Systems Using a New Human-Computer Interaction Educational Methodology, Advanced Learning, Raquel Hijn-Neira (Ed.), ISBN: 978-953-307-010-0, InTech, Available from:

http://www.intechopen.com/books/advanced-learning/enhancing-on-line-blended-learning-systems-using-anew-human-computer-interaction-educational-method

\section{INTECH}

open science | open minds

\section{InTech Europe}

University Campus STeP Ri

Slavka Krautzeka 83/A

51000 Rijeka, Croatia

Phone: +385 (51) 770447

Fax: +385 (51) 686166

www.intechopen.com

\section{InTech China}

Unit 405, Office Block, Hotel Equatorial Shanghai

No.65, Yan An Road (West), Shanghai, 200040, China

中国上海市延安西路65号上海国际贵都大饭店办公楼 405 单元

Phone: +86-21-62489820

Fax: $+86-21-62489821$ 
(C) 2009 The Author(s). Licensee IntechOpen. This chapter is distributed under the terms of the Creative Commons Attribution-NonCommercial-ShareAlike-3.0 License, which permits use, distribution and reproduction for non-commercial purposes, provided the original is properly cited and derivative works building on this content are distributed under the same license. 